\title{
ANALISIS VOLATILITAS RETURN INDEKS SAHAM SEKTOR BARANG KONSUMSI DI INDONESIA: APLIKASI METODE TRESHOLD-GARCH (TGARCH)
}

\section{Analysis of Volatility Return of Consumer Goods Stock Index in Indonesia: Application of Treshold-GARCH Method}

\author{
M. Rismawan Ridha ${ }^{1^{*}}$, Ananto Wibowo ${ }^{2}$ \\ ${ }^{1}$ Badan Pusat Statistik Kabupaten Maluku Tengah, \\ Jl. R.A. Kartini No.15, Maluku Tengah, 97511, Maluku, Indonesia \\ ${ }^{2}$ Badan Pusat Statistik Kabupaten Cianjur \\ Jl. Perintis Kemerdekaan No.3, Cianjur, 43285, Jawa Barat, Indonesia \\ e-mail: rismawan.ridha@bps.go.id ${ }^{l^{*}}$,ananto.wibowo@bps.go.id ${ }^{2}$
}

\begin{abstract}
Abstrak: Sektor barang konsumsi merupakan salah satu sektor yang paling penting dalam perekonomian sebagai penopang bursa saham dalam negeri. Ketika iklim investasi sedang optimal, nilai indeks saham barang konsumsi cenderung meningkat dan volatilitasnya cukup stabil. Namun, saat terjadi guncangan, indeks saham barang konsumsi menunjukkan penurunan nilai dan sangat tidak stabil dengan volatilitas yang tinggi. Penelitian ini bertujuan untuk menguji kemungkinan terjadinya pola asimetris pada data return indeks saham barang konsumsi serta mengetahui apakah goncangan negatif (bad news) dan positif (good news) berbeda pengaruhnya terhadap volatilitas atau leverage effect. Sumber data berasal dari harian indeks saham dengan alat analisis yang digunakan adalah Treshold Generalized Autoregressive Conditional Heteroscedasticity (TGARCH). Hasil penelitian menunjukkan bahwa volatilitas return indeks saham sektor barang konsumsi signifikan dipengaruhi oleh return dan residual satu periode dan tiga periode sebelumnya. Selain itu, terdapat perbedaan yang signifikan antara bad news dan good news, dimana bad news memberikan pengaruh yang lebih besar terhadap volatilitas indeks saham sektor barang konsumsi.
\end{abstract}

Kata Kunci: Volatilitas, Indeks Saham Sektor Barang Konsumsi, TGARCH.

\begin{abstract}
The consumer goods sector is important in the economy as a support for the domestic stock market. When the investment climate is in the optimal state, the index value of consumer goods stocks tends to increase and volatility is quite stable. However, when shocks occur, the consumer goods index shows a decrease in value and is very unstable with high volatility. This study aims to examine the possibility of asymmetrical patterns in the data of the return of the consumer goods stock index and find out whether negative (bad news) and positive (good news) shocks have different effects on volatility (leverage effect). The data source from the daily stock index with the analysis tool used is Threshold Generalized Autoregressive Conditional Heteroscedasticity (TGARCH). The result of the analysis shows that the volatility return of consumer goods stock index significantly influenced by the return and residuals of the previous period and three previous periods. Also, Bad news and Good news significantly differ in influencing the volatility return of consumption goods stock index, where Bad news has a greater impact on the volatility of the consumer goods sector index.
\end{abstract}

Keywords: Volatility, Consumer Goods Stock Index, TGARCH.

\section{PENDAHULUAN}

Terjadinya fluktuasi pada perdagangan saham-saham publik hampir tiap menit menyebabkan harga saham sulit untuk diprediksi [1]. Volatilitas indeks yang cukup tinggi pada IHSG (Indeks Harga Saham Gabungan) atau indeks harga saham yang di keluarkan BEI (Bursa Efek Indonesia) menjadi perhatian para 
Ridha, dkk | Analisis Volatilitas Return Indeks Saham...

investor, manajemen bursa, dan pihak lainnya. Volatilitas sebuah pasar menggambarkan fluktuasi atau perubahan harga pada pasar tersebut [2]. Pada pasar saham, dikenal dengan istilah "high risk high return" yaitu semakin tinggi resiko yang ada, maka semakin tinggi juga keuntungan yang didapatkan para pemegang saham [3]. Investor yang spekulatif lebih suka kepada pasar dengan volatilitas tinggi, karena memungkinkan memperoleh keuntungan dalam waktu yang singkat. Sedangkan, jika volatilitasnya rendah, investor harus memegang saham dalam jangka waktu yang panjang untuk memperoleh keuntungan. Volatilitas yang rendah juga menandakan resiko rendah yang diambil investor untuk menanamkan sahamnya pada pasar saham. Jika resikonya tinggi, maka investasi yang ada akan menjadi sedikit karena ketidakstabilannya kondisi pasar.

BEI mempunyai indeks saham sektoral yang terbagi atas 9 sektor. Klasifikasi ini berdasarkan industri yang telah ditetapkan BEI atau diberi nama dengan JASICA (Jakarta Industrial Classification) [4]. Salah satu sektor tersebut adalah sektor barang konsumsi. Sektor barang konsumsi merupakan sektor yang penting dalam perekonomian Indonesia karena menjadi penopang bursa saham dalam negeri. Sektor ini juga dianggap menarik bagi investor karena pertumbuhan indeksnya yang terbilang paling tinggi diantara sektor-sektor lainnya [5].

Sektor barang konsumsi didominasi oleh saham-saham emiten rokok, seperti PT Gudang Garam Tbk (GGRM) dan PT HM Sampoerna (HMSP) sebagai pendukung utama saham ini. Dominasi saham emiten rokok di sektor barang konsumsi disebabkan oleh Indonesia yang merupakan negara dengan tingkat konsumsi rokok tertinggi se-Asia Tenggara [6], yang di lain sisi, memiliki kontribusi yang besar terhadap penerimaan negara. Walaupun demikian, Saham-saham emiten rokok ini sensitif terhadap berbagai informasi situasional (sentimen) seperti kebijakan kenaikan tarif cukai rokok yang akan berdampak pada pelemahan kinerja keuangan emiten.

Berbagai sentimen pada perekonomian maupun pasar saham yang ada pada saat ini telah memengaruhi kestabilan harga saham. Hal tersebut menunjukkan aset investasi menjadi rentan terhadap gejolak. Keadaan dalam negeri maupun luar negeri turut berdampak kepada pasar saham di Indonesia. Pada periode tertentu, (terutama saat terjadi gejolak perekonomian) indeks saham barang konsumsi menunjukkan penurunan nilai dan sangat tidak stabil dengan volatilitas yang tinggi. Hal berbeda justru terjadi ketika perekonomian dalam keadaan baik dan iklim investasi sedang optimal, nilai indeks saham sektor barang konsumsi meningkat dan volatilitasnya cenderung stabil [7]. Dari keadaan tersebut, terdapat kecenderungan adanya pola asimetris dari peningkatan volatilitas [8]. Volatilitas yang tinggi cenderung terjadi umumnya diakibatkan oleh guncangan negatif daripada saat terjadi guncangan yang bersifat positif. Hal ini menunjukkan bahwa data finansial selalu dikaitkan dengan fenomena ketidaksimetrisan antara nilai guncangan/error positif dan negatif [9].

Studi volatilitas pada saham dan analisis terkait pola asimetris telah banyak dilakukan. Salah satunya oleh Priyono [8] dengan judul "Efek Asimetris dalam Volatilitas Return Indeks LQ45: Pendekatan GJR-GARCH". Temuan pada penelitiannya menunjukkan bahwa data return indeks LQ45 mengalami volatilitas yang tinggi sebagai dampak fluktuasi eksternalitas dari krisis finansial di Amerika. Selain itu, terdapat efek bad news dalam ekonomi yang mengakibatkan peluang return indeks LQ45 akan menurun di periode berikutnya. Penelitian lainnya yang dilakukan oleh Nastiti A, dan Suharsono A [10] dengan hasil studinya didapatkan bahwa return beberapa perusahaan go public memiliki sifat heteroskedastisitas dan sahamnya memiliki potensi resiko yang lebih tinggi dibandingkan saham perusahaan lainnya.

Berdasarkan latar belakang tersebut, peneliti merasa perlu untuk melakukan studi mengenai ada tidaknya pola asimetris pada data return indeks saham barang konsumsi. Penelitian ini juga ingin mengetahui apakah goncangan negatif (bad news) dan goncangan positif (good news) berbeda pengaruhnya terhadap volatilitas atau terjadinya leverage effect pada data return saham sektor barang konsumsi. 


\section{METODOLOGI}

\subsection{Sumber dan Jenis Data}

Sumber data dalam analisis ini adalah data sekunder. Data yang digunakan merupakan data harian indeks saham sektor barang konsumsi periode Juli 2014 - Juli 2016 pada saat penutupan yang diperoleh dari duniainvestasi.com yang tersambung ke Bursa Efek Indonesia. Sebelum data yang di kumpulkan diolah, terlebih dahulu data indeks saham diubah menjadi data return indeks saham dengan cara, indeks saham hari ke- $t$ dikurangi dengan indeks saham hari ke $t-1$, dibagi dengan indeks saham hari ke $t-1$ [11]. Persamaan secara sistematis sebagai berikut:

$$
\operatorname{Return}(t)=\left(P_{t}-P_{t-1}\right) / P_{t-1}
$$

\subsection{Metode Analisis}

Metode analisis yang digunakan pada penelitian ini adalah analisis deskriptif dan analisis time series untuk mengetahui volatilitas return indeks saham barang konsumsi dengan menggunakan software Microsoft Excel dan E-views 9.0. Analisis time series yang digunakan adalah analisis Treshold Generalized Autoregressive Conditional Heteroscedasticity (TGARCH) untuk memodelkan volatilitas return indeks saham barang konsumsi.

Langkah analisis dimulai dengan membuat time series plot dan menghitung statistik deskriptif return indeks saham sektor barang konsumsi. Langkah berikutnya melakukan uji stasioneritas dengan menggunakan uji Augmented Dickey Fuller (ADF). Misalkan terdapat terdapat model $A R(1)$ dengan persamaan:

$$
\text { Return }_{t}=\emptyset_{1} \text { Return }_{t-1}+Z_{t}
$$

Maka dikatakan stasioner jika $\left|\emptyset_{1}\right|<1$ [12]. Data yang telah stasioner dibuat plot correlogram Autocorrelation Function (ACF) dan Partial Autocorrelation Function (PACF) yang digunakan untuk pendugaan orde ARIMA.

Berdasarkan hasil ini, kemudian dilakukan estimasi, uji signifikansi parameter dan uji diagnosa residual. Model yang terbaik dipilih berdasarkan nilai AIC (Akaike Information Criterion) dan SC (Schwardz Criterion) yang terkecil. Residual yang diperoleh dari model ARIMA terbaik diuji apakah terdapat efek ARCH dengan uji LM. Jika diketahui terdapat efek ARCH (adanya heteroskedastisitas) berarti layak dilanjutkan dengan pemodelan menggunakan ARCH/GARCH [10].

Pada beberapa data finansial, terdapat perbedaan besarnya perubahan pada volatilitas ketika terjadi pergerakan nilai return, yang disebut dengan pengaruh keasimetrikan [13]. Metode TGARCH yang digunakan ini bertujuan untuk menghasilkan model volatilitas yang sistematik dengan menambahkan variabel dummy untuk mengakomodir kemungkinan terjadinya pengaruh keasimetrikan dan volatilitas suatu variabel sebagai akibat adanya Bad news dan Good news [14].

\section{HASIL DAN PEMBAHASAN}

\subsection{Analisis Deskriptif}

Dalam bidang finansial, istilah return dikenal sebagai besarnya pengembalian yang akan diperoleh sebagai hasil dari suatu kegiatan investasi. Return indeks saham sektor barang konsumsi periode Juli 2014 - Juli 2016 menunjukkan keadaan volatilitas yang tinggi. Hal ini dapat dilihat dari pergerakan return perusahaan di sektor ini yang sangat tidak stabil, dimana rentang nilainya berkisar dari -0,04 sampai 0,06 setiap harinya. Nilai return tertinggi yakni sebesar 0,054 sedangkan nilai return terendah adalah $-0,037$. Untuk mendapatkan informasi yang lebih komprehensif dan melihat lebih lanjut sebaran data return pada indeks sektor barang konsumsi, maka digunakan statistik deskriptif seperti Gambar 1. 

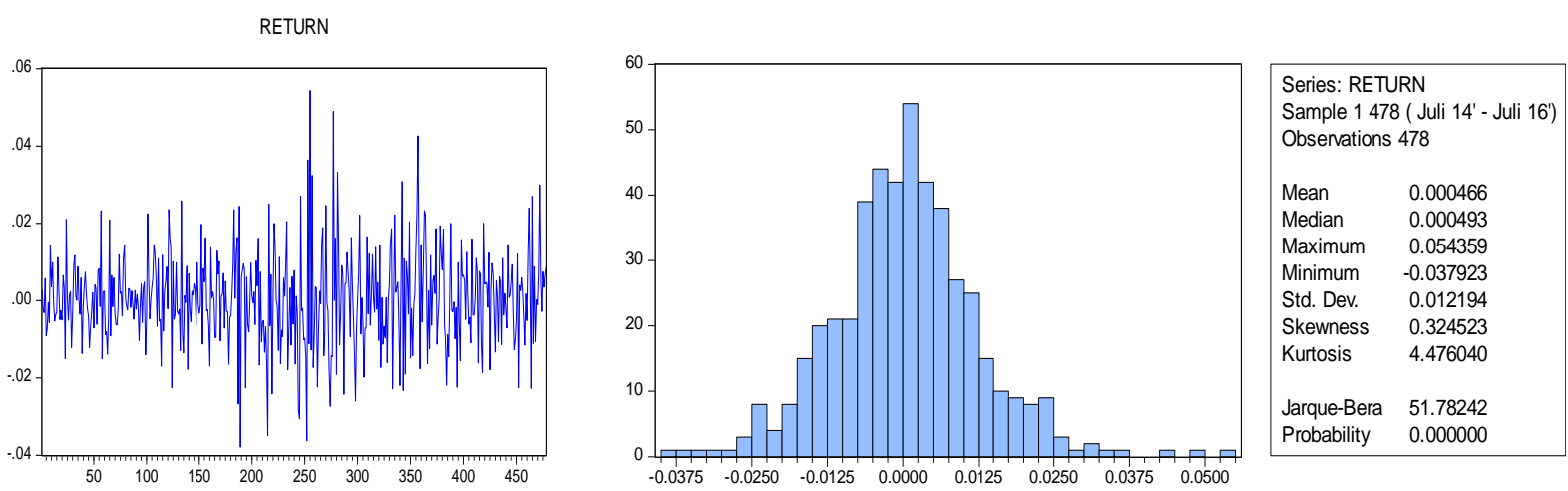

Gambar 1. Statistik Deskriptif Return Indeks Sektor Barang Konsumsi Periode Juli 2014 - Juli 2016

Dari gambar tersebut dapat dilihat bahwa rata-rata return indeks saham barang konsumsi adalah sebesar 0,000466, atau dapat diartikan bahwa tingkat pengembalian pada sektor barang konsumsi selama periode penelitian mencapai sekitar 0,05 persen tiap harinya. Sebarannya juga tidak mengikuti distribusi normal yang bisa dilihat dari keruncingan (kurtosis) yang mencapai 4,47, dimana melebihi nilai normal kurtosis yaitu 3 [15]. Nilai kurtosis yang sangat besar (bernilai positif) mengindikasikan bahwa sebarannya memiliki ekor yang lebih panjang dari sebaran normal. Hal ini dapat dibuktikan oleh Uji Jarque-Bera dengan nilai sebesar 51,78 dengan probability 0,0000 (p-value $<0,05$, yang berarti menolak Ho dan kesimpulannya data tidak berdistribusi normal). Jika data tidak mengikuti distribusi normal, dengan indikasi nilai kurtosis yang besar (di atas 3), maka terdapat kecenderungan bahwa sifat dari data dipengaruhi oleh proses ARCH atau adanya pola asimetrik [16].

\subsection{Analisis Inferensia}

\section{Uji Stasioneritas dan Pemilihan Ordo AR, MA, serta Pemodelan ARIMA}

Pengujian stasioneritas dengan menggunakan metode Augmented Dickey Fuller-test (ADF-test), pada intercept dan tanpa tren. Hasil yang didapat adalah sebagai berikut:

Null Hypothesis: RETURN has a unit root

Exogenous: Constant

Lag Length: 0 (Automatic - based on SIC, maxlag=17)

\begin{tabular}{lrrr}
\hline \hline & t-Statistic & Prob.* \\
\hline \hline Augmented Dickey-Fuller test statistic & -24.73051 & 0.0000 \\
\hline Test critical values: & $1 \%$ level & -3.443834 & \\
& $5 \%$ level & -2.867379 & \\
& $10 \%$ level & -2.569943 & \\
\hline \hline
\end{tabular}

*MacKinnon (1996) one-sided p-values.

Gambar 2. Hasil uji stasioneritas Return pada level

Berdasarkan hasil pengujian stasioneritas, pada tingkat signifikansi 5\% menunjukkan bahwa return indeks barang konsumsi telah stasioner pada tingkat level. Tahapan selanjutnya adalah melakukan Pemilihan Ordo AR, MA atau ARMA. 


\begin{tabular}{|c|c|c|c|c|c|c|}
\hline Autocorrelation & Partial Correlation & & $\mathrm{AC}$ & PAC & Q-Stat & Prob \\
\hline 다 & 다 & 1 & -0.126 & -0.126 & 7.6393 & 0.006 \\
\hline ip & יני & 2 & 0.076 & 0.061 & 10.400 & 0.006 \\
\hline 与. & 5. & 3 & -0.119 & -0.105 & 17.258 & 0.001 \\
\hline ים & 14 & 4 & -0.027 & -0.059 & 17.605 & 0.001 \\
\hline ים 1י & 1. & 5 & -0.037 & -0.035 & 18.281 & 0.003 \\
\hline S1 & 5. & 6 & -0.099 & -0.119 & 23.030 & 0.001 \\
\hline ip & Pי & 7 & 0.093 & 0.064 & 27.268 & 0.000 \\
\hline 11 & 1 & 8 & -0.020 & -0.000 & 27.460 & 0.001 \\
\hline 叫 & 4. & 9 & -0.058 & -0.103 & 29.131 & 0.001 \\
\hline י & ין & 10 & 0.059 & 0.054 & 30.851 & 0.001 \\
\hline $1 \sqrt{1}$ & 15 & 11 & 0.034 & 0.053 & 31.412 & 0.001 \\
\hline 11 & ים & 12 & -0.021 & -0.047 & 31.638 & 0.002 \\
\hline ים 1 & 14 & 13 & -0.038 & -0.027 & 32.365 & 0.002 \\
\hline 1$] 1$ & $1] 1$ & 14 & -0.000 & -0.005 & 32.365 & 0.004 \\
\hline י Pי & יוpי & 15 & 0.042 & 0.032 & 33.228 & 0.004 \\
\hline \begin{tabular}{l|l}
1 & 1
\end{tabular} & יקי & 16 & 0.004 & 0.034 & 33.235 & 0.007 \\
\hline 11 & $1 / 1$ & 17 & 0.011 & 0.001 & 33.297 & 0.010 \\
\hline 1 & 111 & 18 & 0.004 & -0.010 & 33.304 & 0.015 \\
\hline
\end{tabular}

Gambar 3. Correlogram Autoregressive dan Moving Average

Analisis correlogram atau yang biasa dikenal dengan plot autokorelasi antarwaktu, digunakan untuk mengetahui pada ordo berapakah AR, MA atau keduanya signifikan memengaruhi return indeks barang sektor konsumsi [17]. Dilihat dari correlogram yang signifikan yaitu yang keluar dari confidence intervalnya, ada AR(1), AR(3), MA(1) dan MA(3). Selanjutnya dilakukan estimasi dengan menggunakan model $\mathrm{AR}(1), \mathrm{AR}(3), \mathrm{MA}(1)$ dan MA(3) dan didapat hasil output E-views sebagai berikut:

\begin{tabular}{|c|c|c|c|c|}
\hline Variable & Coefficient & Std. Error & t-Statistic & Prob. \\
\hline $\mathrm{C}$ & 0.000449 & 0.000395 & 1.137623 & 0.2559 \\
\hline $\operatorname{AR}(1)$ & -0.382647 & 0.043786 & -8.738962 & 0.0000 \\
\hline AR(3) & 0.668016 & 0.041376 & 16.14515 & 0.0000 \\
\hline $\mathrm{MA}(1)$ & 0.322210 & 0.026058 & 12.36493 & 0.0000 \\
\hline $\mathrm{MA}(3)$ & -0.805440 & 0.024968 & -32.25863 & 0.0000 \\
\hline R-squared & 0.056382 & \multicolumn{2}{|c|}{ Mean dependent var } & 0.000466 \\
\hline Adjusted R-squared & 0.048402 & \multicolumn{2}{|c|}{ S.D. dependent var } & 0.012194 \\
\hline S.E. of regression & 0.011896 & \multicolumn{2}{|c|}{ Akaike info criterion } & -6.012610 \\
\hline Sum squared resid & 0.066932 & \multicolumn{2}{|c|}{ Schwarz criterion } & -5.968995 \\
\hline Log likelihood & 1442.014 & \multicolumn{2}{|c|}{ Hannan-Quinn criter. } & -5.995463 \\
\hline F-statistic & 7.065503 & \multirow{2}{*}{\multicolumn{2}{|c|}{ Durbin-Watson stat }} & 2.096666 \\
\hline Prob(F-statistic) & 0.000016 & & & \\
\hline
\end{tabular}

Gambar 4. Output pemodelan AR(1) AR(3) MA(1) MA(3)

Berdasarkan hasil pemodelan diatas, didapatkan persamaan model ARMA yaitu:

$$
\operatorname{Return}_{(t)}=0,00044-0,3826 \operatorname{Return}_{(t-1)}{ }^{*}+0,6680 \operatorname{Return}_{(t-3)}{ }^{*}+0,3222 \varepsilon_{t-1}{ }^{*}-0,8054 \varepsilon_{t-3}{ }^{*}
$$

Keterangan: (*) Signifikan pada taraf $5 \%$.

Hasil estimasi tersebut merupakan model terbaik yang didapat, dengan pertimbangan pemilihan model terbaik berdasarkan kriteria nilai AIC dan SC yang lebih kecil jika dibandingkan dengan ordo-ordo ARMA lainnya [18]. Model tersebut menyatakan bahwa nilai return ke- $t$ dipengaruhi oleh nilai return dan residual pada lag sebelumnya $(t-1)$ dan tiga lag sebelumnya $(t-3)$. Selanjutnya, dilakukan uji heteroskedastisitas residual dari model ARMA tersebut, dengan menggunakan ARCH-LM test, didapat hasil sebagai berikut:

Heteroskedasticity Test: ARCH

\begin{tabular}{llll}
\hline \hline F-statistic & 11.90800 & Prob. F(2,473) & 0.0000 \\
Obs*R-squared & 22.81814 & Prob. Chi-Square(2) & 0.0000 \\
& $=$
\end{tabular}

Gambar 5. Output Pengujian Heteroskedastisitas ARCH-LM 
Ridha, dkk | Analisis Volatilitas Return Indeks Saham...

Dari hasil tersebut dapat dilihat nilai Prob (F-statistic) adalah 0,0000, jika dibandingkan dengan tingkat signifikansi 5\% atau 0,05, maka kita dapat menolak $H_{o}$ dan simpulkan bahwa terdapat heteroskedastisitas pada residual. Hal ini menandakan bahwa variansnya yang tidak konstan antar waktu sehingga estimator yang dihasilkan tidak efisien atau varians dari estimator tidak minimum [19]. Untuk mengatasi permasalahan tersebut, digunakan teknik Treshold-GARCH untuk memodelkan data return.

\section{Treshold Generalized Autoregressive Conditional Heteroscedasticity (TGARCH)}

Selanjutnya, dilakukan pemodelan dengan menggunakan Treshold-GARCH dikarenakan jika menggunakan model ARIMA dan residualnya bersifat heteroskedastis, maka varians yang dihasilkan tidak akan konstan antar waktu sehingga akan menyulitkan dalam melakukan estimasi parameter dan peramalan. Tidak seperti ARIMA yang menggunakan Ordinary Least Square (OLS), estimasi yang digunakan pada metode ini adalah estimasi fungsi Maximum Likelihood. Hasil estimasi pemodelan data return indeks saham barang konsumsi menggunakan Model TGARCH(1,1) ditunjukkan oleh Gambar 6.

\begin{tabular}{|c|c|c|c|c|}
\hline Variable & Coefficient & Std. Error & z-Statistic & Prob. \\
\hline C & 0.000321 & 0.000367 & 0.875140 & 0.3815 \\
\hline $\operatorname{AR}(1)$ & -0.446741 & 0.053145 & -8.406072 & 0.0000 \\
\hline AR(3) & 0.640736 & 0.052334 & 12.24310 & 0.0000 \\
\hline MA(1) & 0.369774 & 0.034943 & 10.58211 & 0.0000 \\
\hline MA(3) & -0.764588 & 0.036022 & -21.22575 & 0.0000 \\
\hline \multicolumn{5}{|c|}{ Variance Equation } \\
\hline C & 3.93E-06 & $2.13 E-06$ & 1.843327 & 0.0653 \\
\hline $\operatorname{RESID}(-1)^{\wedge} 2$ & 0.045407 & 0.027376 & 1.658641 & 0.0972 \\
\hline $\operatorname{RESID}(-1)^{n} 2^{\star}(\operatorname{RESID}(-1)<0)$ & 0.081429 & 0.041160 & 1.978338 & 0.0479 \\
\hline GARCH $(-1)$ & 0.890975 & 0.037714 & 23.62429 & 0.0000 \\
\hline R-squared & 0.053712 & \multicolumn{2}{|c|}{ Mean dependent var } & 0.000466 \\
\hline Adjusted R-squared & 0.045710 & \multirow{2}{*}{\multicolumn{2}{|c|}{$\begin{array}{l}\text { S.D. dependent var } \\
\text { Akaike info criterion }\end{array}$}} & 0.012194 \\
\hline S.E. of regression & 0.011912 & & & -6.120178 \\
\hline Sum squared resid & 0.067121 & \multicolumn{2}{|c|}{ Schwarz criterion } & -6.041671 \\
\hline Log likelihood & 1471.723 & \multirow{2}{*}{\multicolumn{2}{|c|}{ Hannan-Quinn criter. }} & -6.089313 \\
\hline Durbin-Watson stat & 2.066573 & & & \\
\hline
\end{tabular}

Gambar 6. Output Pemodelan TGARCH $(1,1)$

Conditional Mean Equation:

$$
\operatorname{Return}_{(t)}=0,00032-0,4467 \operatorname{Return}_{(t-1)}{ }^{*}+0,6407 \operatorname{Return}_{(t-3)}{ }^{*}+0,3697 \varepsilon_{t-1}{ }^{*}-0,7645 \varepsilon_{t-3}{ }^{*}
$$

Conditional Variance Equation:

$$
\sigma^{2}{ }_{t}=0,0000039+0,0454 \varepsilon^{2}{ }_{t-1}+0,08143 \varepsilon^{2}{ }_{t-1} d_{t-1}{ }^{*}+0,8909 \sigma^{2}{ }_{t-1}{ }^{*}
$$

Keterangan: (*) Signifikan pada taraf 5\%

Pada persamaan mean model dengan taraf signifikansi 5\%, nilai return ke- $t$ dipengaruhi oleh nilai return dan residual baik hari sebelumnya maupun 3 hari sebelumnya. Hal ini menunjukkan bahwa tingkat pengembalian indeks saham barang konsumsi secara langsung dipengaruhi oleh guncangan atau shock pada hari sebelumnya juga 3 hari sebelumnya.

Pada persamaan varians model dengan taraf signifikansi 5\%, varians return dipengaruhi oleh varians return di hari sebelumnya. Selain itu, koefisien variabel dummy threshold sebesar 0,0814 menunjukkan hasil yang signifikan. Ini berarti terdapat pengaruh keasimetrikan atau adanya perbedaan besarnya perubahan volatilitas ketika terjadi pergerakan nilai return.

Efek leverage yang ditunjukkan pada koefisien variabel dummy threshold yang bernilai positif $\left(\gamma_{i}>0\right)$ berarti bahwa bad news (guncangan negatif) memiliki efek yang lebih kuat dibandingkan good news (guncangan positif) [20]. Ketika terjadi perubahan pada pergerakan nilai return, volatilitas cenderung menurun ketika return naik dan akan meningkat ketika return melemah. Saat guncangan negatif (bad $n e w s)$ pada hari sebelumnya dan 3 hari sebelumnya yakni saat $\varepsilon_{t-1}$ dan $\varepsilon_{t-3}$ bernilai negatif, hal ini akan berdampak besar sehingga volatilitas meningkat dan akan menurunkan nilai return. Sebaliknya, saat guncangan positif (good news) dimana nilai $\varepsilon_{t-1}$ dan $\varepsilon_{t-3}$ bernilai positif akan menurunkan volatilitas 
yang berdampak pada naiknya nilai return. Pengaruh keasimetrikan ini terjadi akibat adanya volatilitas yang sangat besar pada pasar saham sektor barang konsumsi dengan tingkat resiko yang besar dalam memegang suatu aset.

Selanjutnya, kita kembali melakukan pegujian ARCH-LM dan uji normalitas Jarque Bera untuk mengetahui apakah masih terdapat pengaruh efek ARCH (masalah pada heteroskedastisitas). Hasil pengujian ARCH-LM dan uji normalitas ditunjukkan oleh Gambar 7 dan 8.

\begin{tabular}{llll}
\multicolumn{4}{l}{ Heteroskedasticity Test: ARCH } \\
\hline \hline F-statistic & 2.113219 & Prob. F(2,473) & 0.1220 \\
Obs*R-squared & 4.215577 & Prob. Chi-Square(2) & 0.1215 \\
\hline \hline
\end{tabular}

Gambar 7. Output pengujian Heteroskedastisitas ARCH-LM dengan Model TGARCH(1,1)

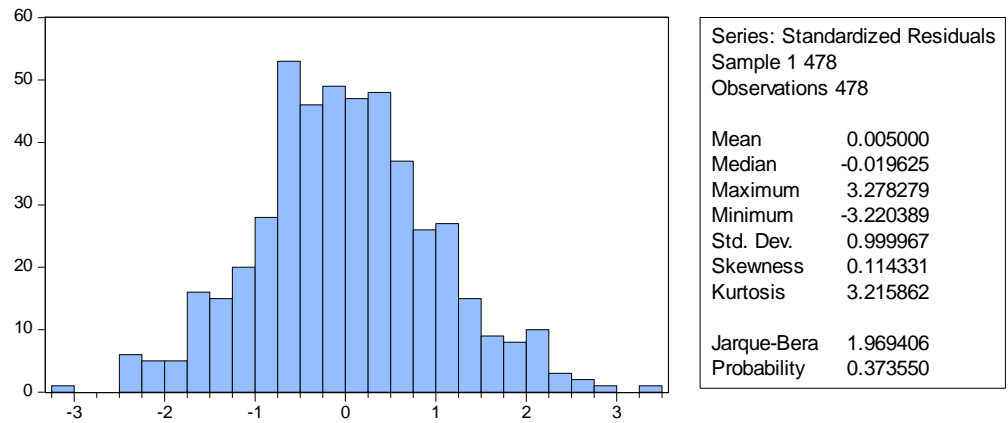

Gambar 8. Output Uji Normalitas Jarque-Bera dengan Model TGARCH(1,1)

Dari hasil tersebut dapat dilihat bahwa pada taraf signifikansi 5\% tidak terdapat masalah heteroskedastisitas yang menandakan bahwa residual bersifat homoskedastis atau memiliki varians yang konstan antar waktu. Selain itu, berdasarkan hasil pengujian normalitas residual, $p$-value uji Jarque-Bera sebesar 0,3735 ( $p$-value >0,05) menyimpulkan bahwa asumsi normalitas telah terpenuhi dan efek ARCH telah hilang di dalam model. Hasil kedua pengujian juga menandakan bahwa model telah layak serta bisa digunakan untuk memodelkan volatilitas return indeks saham sektor barang konsumsi.

\section{KESIMPULAN}

Berdasarkan hasil analisis dan pembahasan maka diperoleh beberapa kesimpulan sebagai berikut: (1) Terdapat pola asimetris pada data return indeks saham sektor barang konsumsi sehingga dapat digunakan teknik TGARCH; (2) Volatilitas return indeks saham sektor barang konsumsi signifikan dipengaruhi oleh return dan residual satu periode dan tiga periode sebelumnya; (3) dummy threshold (efek asimetris) yang signifikan menujukkan bahwa bad news memiliki dampak yang lebih besar jika dibandingkan dengan good news terhadap pergerakan volatilitas return indeks saham sektor barang konsumsi.

Untuk penelitian selanjutnya, selain menganalisis return, sebaiknya dapat juga menganalisis nilai Value at Risk (VaR) dinamik saham perusahaan pada sektor barang konsumsi. Selain itu, dalam pemodelan analisis volatilitas, dapat juga digunakan model ARCH-GARCH lainnya seperti EGARCH dan IGARCH. 
Ridha, dkk | Analisis Volatilitas Return Indeks Saham...

\section{DAFTAR PUSTAKA}

[1] Kamaludin, Struktur Volatilitas Pendekatan ARCH GARCH. Jurnal Media Riset Bisnis dan Manajemen Vol. 8, No. 2, 2008

[2] Sitanggang, M.S., \& Hidayat, P., Analisis Kausalitas antara Volatilitas Saham dengan Variabel Makroekonomi Indonesia. Jurnal Ekonomi dan Keuangan Vol. 1, No. 5, Universitas Sumatera Utara: 2013

[3] Farida, M., \& Darmawan, A., Pengaruh Risiko Inflasi, Risiko Suku Bunga, Risiko Valuta Asing, dan Profitabilitas terhadap Return Saham. Jurnal Administrasi Bisnis (JAB) Vol. 50 No.1, Universitas Brawijaya: 2017

[4] Indonesia Stock Exchange., Buku Panduan Indeks Harga Saham Bursa Efek Indonesia. Jakarta: 2010

[5] Massijaya, N.K., Pengaruh Variabel Makroekonomi Terhadap Harga Saham Perusahaan Sektor Consumer Goods pada Indeks LQ45. Skripsi, Fakultas Ekonomi dan Manajemen, Institut Pertanian Bogor: 2015

[6] ASEAN Tobacco Tax Report Card., Regional Comparisons and Trends. Southeast Asia Tobacco Controll Alliance (SEATCA): 2014

[7] Gunadi, I., Taruna, A.A., \& Harun, A.C., Penggunaan Indeks Stabilitas Sistem Keuangan (ISSK) Dalam Pelaksanaan Surveilans Makroprudensial. Working Paper, WP/15/2013, Bank Indonesia: 2013

[8] Priyono, A.F., Efek Asimetris dalam Volatilitas Return Indeks LQ45: Pendekatan GJR: GARCH. Jurnal Manajemen Indonesia Vol. 12, No. 2 Agustus: 2012

[9] Tsay, R.S., Analysis of Financial Time Series. John Wiley and Sons inc. Canada: 2002

[10] Nastiti, A., \& Suharsono, A., Analisis Volatilitas Saham Perusahaan Go Public dengan Metode ARCH-GARCH. Jurnal Sains dan Seni ITS Vol .1, No.1: 2012

[11] Paramitha, G., Nugroho W.H., \& Kusdarwati, H., Perbandingan Model Volatilitas Data Return dengan Menggunakan Model Exponentially Generalized Autoregressive Conditional Heteroscedasticity (EGARCH)(1,1), dan Threshold Generalized Autoregressive Conditional Heteroscedasticity (TGARCH)(1,1) (Pada Data Indeks Harga Saham Gabungan dan Swiss Market Indeks). Jurnal Mahasiswa Statistik, Vol. 1, No.14, Universitas Brawijaya: 2013.

[12] Baumöhl E. \& Lyócsa S., (2009). Stationarity of Time Series and the Problem of Spurious Regression. MPRA Paper 27926, University Library of Munich, Germany.

[13] Untari, N., Mattjik, A,A., \& Saefuddin, A., Analisis Deret Waktu dengan Ragam Galat Heterogen dan Asimetrik : Studi Indeks Harga Saham Gabungan (IHSG) Periode 1999-2008. Forum Statistika dan Komputasi: 2009

[14] Juanda, B., \& Junaidi., Ekonometrika Deret Waktu: Teori dan Aplikasi. IPB Press. Bogor: 2012

[15] Lawford, S., Finite-sample quantiles of the Jarque-Bera Test. Journal of Applied Economic Letters, Vol. 12: 2005

[16] Lo, M.S., Generalized Autoregressive Conditional Heteroscedasticity Time Series Models. Thesis. Departement of Statistics and Actuarial Science. Simon Fraser University: 2003 
[17] Enders, W., Application of Econometric Time Series Second Edition. John Wiley and Sons, Inc. New York: 2004

[18] Nachrowi, N.D., \& Usman, H,. Pendekatan Populer dan Praktis Ekonometrika Untuk Analisis Ekonomi dan Keuangan. LP FEUI. Jakarta: 2006

[19] Gujarati, N.D., \& Porter D.C., Basic Econometrics: Fifth Edition. McGraw-Hill Companies Inc, New York: 2009.

[20] Dahlvid, C., \& Granberg, P., The Leverage Effect: Uncovering the true nature of U.S assymetric volatility. Master Thesis. Lund University: 2017. 